\title{
Synovial Chlamydia trachomatis up regulates expression of a panel of genes similar to that transcribed by Mycobacterium tuberculosis during persistent infection
}

\author{
H C Gérard, J A Whittum-Hudson, H R Schumacher, A P Hudson

See end of article for authors' affiliations

Correspondence to Dr A P Hudson

Department of

Immunology and

Microbiology, Wayne

State University School of

Medicine, Gordon H Scott

Hall, 540 East Canfield

Avenue Detroit Ml 48201

USA; ahudson@

med.wayne.edu

Accepted

21 September 2005

Published Online First

28 September 2005
Background: Synovial tissues in patients with Chlamydia associated arthritis are persistently infected by $C$ trachomatis, an organism for which genetic manipulation is not possible. M tuberculosis also engages in persistent infection, and because this bacterium is genetically tractable many groups have been able to define transcriptional characteristics of mycobacterial growth and persistence.

Objective: To investigate whether the pattern of gene expression underlying chlamydial persistence is similar to that underlying mycobacterial persistence.

Methods: 194 genes in $M$ tuberculosis that are transcriptionally up regulated to support in vivo growth and persistence of that organism have previously been identified. Each of those genes was compared with the C trachomatis genome to identify orthologues. Expression of selected chlamydial orthologues so identified was assessed by real time RT-PCR in an in vitro model of chlamydial persistence and synovial tissues from patients who were PCR positive for $C$ trachomatis at that site.

Results: 67 C trachomatis genes were identified as being orthologous to mycobacterial persistence related genes, representing $35 \%$ of the genes tested. The chlamydial orthologues fell into similar metabolic and other categories as those in $M$ tuberculosis. Expression of a majority of selected chlamydial orthologues was strongly up regulated in an in vitro model of chlamydial persistence and in synovial tissues of relevant patients, compared with their expression during active infection.

Conclusions: These observations provide new insight into the molecular genetic basis underlying chlamydial persistence, and indicate that this information can be obtained, in some instances, by extrapolating observations made in other biological systems and/or organisms.
A n obligate intracellular pathogen, Chlamydia trachomatis, is the most prevalent sexually transmitted bacterium in America and other developed countries. ${ }^{1}$ An often severe acute inflammatory arthritis develops in some subjects with a prior urogenital infection with this organism, and about half of all patients who develop acute arthritis progress to chronic disease (reviewed by Villareal et al ${ }^{2}$ and Gérard $e t a l^{3}$ ). The reason(s) that only a limited number of patients with a genital chlamydial infection develop acute arthritis is/are poorly understood. We also do not understand why only a portion of subjects with acute disease progress to chronicity, although both issues relate to our lack of detailed understanding of host-pathogen interaction during synovial chlamydial infection.

C trachomatis undergoes a biphasic developmental cycle at its sites of primary infection, the urethral or cervical epithelium (reviewed by $\mathrm{Hatch}^{4}$ ). This organism can disseminate widely from those primary infection sites, and when it does so the vehicle of its dissemination is the monocytic cell, the cell type which is the primary synovial host in both acute and chronic Chlamydia-induced arthritis. ${ }^{45}$ In contrast with the normal progression through the developmental cycle undergone during active infection of epithelial cells, however, $C$ trachomatis residing within monocytic cells in the joint pass rapidly into an unusual biological state designated "persistence". ${ }^{3}$ In this state, the organisms are morphologically aberrant, non-culturable by standard laboratory methods, resistant to antibiotics, and they display an unusual transcript profile. ${ }^{6-12} C$ pneumoniae, a human respiratory pathogen related to $C$ trachomatis, has also been implicated in eliciting inflammatory arthritis, and this organism too has been shown to cause persistent infection under some circumstances. ${ }^{13}{ }^{14}$

It seems clear that synovial pathogenesis in Chlamydiainduced arthritis is a function of persistent, rather than normal active, infection. However, details relating to the mechanism(s) by which chlamydiae enter, and thereafter maintain, the persistent infection state in vivo, as well as details about the means by which persistent chlamydiae elicit disease, remain to be elucidated. As mentioned, persistent chlamydiae display an unusual transcript profile compared with that of active infection. For example, expression of ompl, the gene encoding the major outer membrane protein, is severely attenuated in persistence. ${ }^{7}$ Genes encoding products required for DNA replication (for example, dnaA, polA, and others) are transcribed in persistently infecting $C$ trachomatis cells as they are during active infection, but expression of genes specifying products required for cytokinesis is severely down regulated during persistence (for example, ftsK, $\left.f t s W^{8}\right)$. Several other chlamydial genes of known function are also differentially expressed in persistent $v$ active infection. ${ }^{3910}$ Full understanding of the genetic programme underlying entry into and maintenance of chlamydial persistence will be a difficult task, because many coding sequences on the $C$ trachomatis and $C$ pneumoniae genomes specify products of unknown function. ${ }^{15}{ }^{16}$ To complicate matters further, no system for genetic manipulation of either pathogen exists to date.

Bacterial pathogens other than $C$ trachomatis and $C$ pneumoniae take part in persistent infection, and in some 


$\begin{aligned} & \text { Table } 1 \\
& \text { this study }\end{aligned}$
\begin{tabular}{llll} 
Patient & Sex/age & Diagnosis & $\begin{array}{l}\text { Disease duration } \\
\text { (months) }\end{array}$ \\
\hline 1 & $M / 62$ & RA & 84 \\
2 & F 60 & UO & 72 \\
3 & M/48 & ReA & 36 \\
\hline
\end{tabular}
RA, rheumatoid arthritis; UO, undifferentiated oligoarthritis;
ReA, reactive arthritis.

cases the mechanisms by which those organisms establish persistence have been studied extensively. Mycobacterium tuberculosis, in which genetic manipulation is possible and for which the full genome sequence is available, is one such organism. ${ }^{17}{ }^{18}$. Studies from several laboratories have defined many critical aspects underlying mycobacterial persistence. ${ }^{19-21}$ For example, one recent investigation of genes required for in vivo growth and persistence of $M$ tuberculosis in an animal model of disease identified 194 coding sequences required for those processes. ${ }^{22}$ Virtually all of the genes identified in that study as being required for establishment of persistence were not expressed, or were expressed at only low level, during axenic growth of the organism.

Because genetic manipulation of Chlamydia is not available, identification of chlamydial genes orthologous to those shown to function in persistence in other organisms may be of value. We undertook a study to determine whether none, some, or all of the 194 genes shown to be transcriptionally up regulated in support of growth and persistence in vivo for $M$ tuberculosis have orthologues in $C$ trachomatis. We report that $35 \%$ of the coding sequences identified in the mycobacterial study have related genes in $C$ trachomatis. We further show that a selected set of those chlamydial orthologues spanning several metabolic and other categories show up regulation of expression during persistence, as in $M$ tuberculosis, in both an in vitro model of that infection state and in samples from patients with arthritis who are polymerase chain reaction (PCR) positive for the organism in synovial tissue.

\section{PATIENTS AND METHODS \\ Patient samples}

Synovial biopsy specimens were procured under an approved protocol from patients attending the Arthritis Clinics at the V.A. Medical Center and the University of Pennsylvania Hospital, Philadelphia PA, USA; protocol approval was from the University of Pennsylvania School of Medicine and Wayne State University School of Medicine IRB committees. Synovial biopsy specimens were obtained by the ParkerPearson method and were immediately snap frozen at $-80^{\circ} \mathrm{C}$ until prepared for analyses. ${ }^{23}$ The three patients studied were included solely because they were PCR positive for $C$ trachomatis chromosomal DNA in synovial tissues, and because enough tissue was present from each to support the several molecular genetic analyses required. Diagnoses for the patients were made according to criteria of the American College of Rheumatology. Table 1 summarises the clinical characteristics of each patient from whom samples were obtained.

\section{Cell growth, in vitro infection with $C$ trachomatis}

HEp-2 cells support active growth of $C$ trachomatis ${ }^{814}$-that is, Chlamydia infecting this cell line progress normally through the developmental cycle. Nearly confluent monolayers of HEp-2 cells were infected with $C$ trachomatis $\mathrm{K}$ serovar at a multiplicity of infection of $1: 1$ in the standard manner. ${ }^{8}{ }^{9}$ Infected cultures were harvested at 12 hours after infection,
Table 2 C trachomatis genes targeted and primer sequences for real time RT-PCR

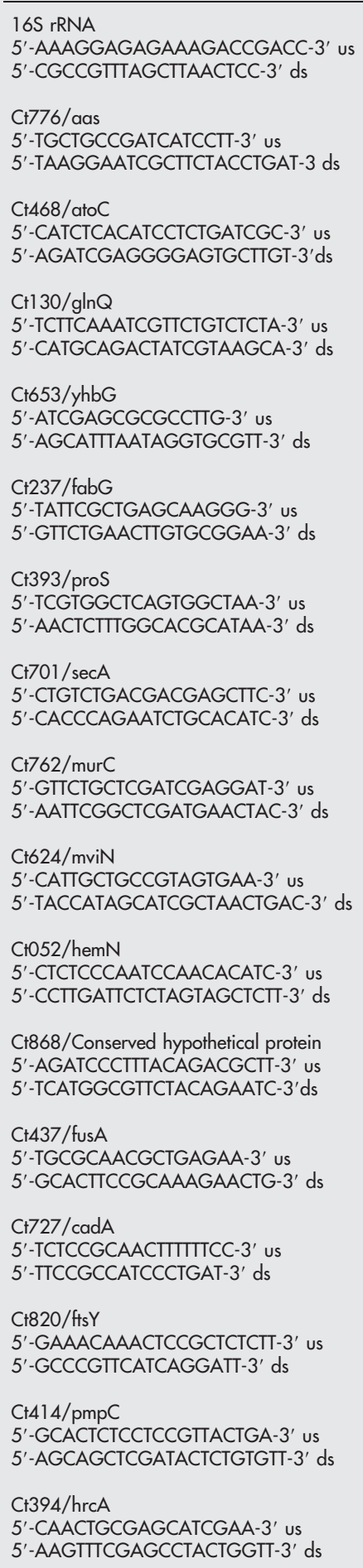

and cell pellets were snap frozen at $-80^{\circ} \mathrm{C}$ until processed for analysis. $C$ trachomatis infecting normal human peripheral monocytes in culture enter the persistent infection state by day 3 after infection. ${ }^{7-10}$ Blood samples were procured from volunteer donors under an approved protocol, and monocytic cells were prepared and entered into culture as described by $\mathrm{us}^{6-10}$; the protocol was approved by the Wayne State University School of Medicine IRB. Nearly confluent monolayers of 
Table 3 C trachomatis genes identified in the BLAST search using M tuberculosis persistence related genes as query

\begin{tabular}{|c|c|c|c|}
\hline $\begin{array}{l}\text { Metabolism gene ID/ } \\
\text { name* }\end{array}$ & $\begin{array}{l}C \text { trachomatis gene ID/ } \\
\text { name† }\end{array}$ & Gene function & E value \\
\hline \multicolumn{4}{|l|}{ Metabolism: } \\
\hline Rv3114/UNK & $\mathrm{C}+844 / y$ thC & Cytosine deaminase & $6.00 \mathrm{E}-04$ \\
\hline Rv2976c/ung & $\mathrm{C}+067 / y+g A$ & $\mathrm{~N}$-Uracyl glycosylase & $1.00 \mathrm{E}-34$ \\
\hline Rv3868/UNK & Ct040/ruvB & Holliday Junction DNA helicase & $2.00 \mathrm{E}-05$ \\
\hline Rv2241/aceE & $C+750 / t k+B$ & Transketolase & $9.00 \mathrm{E}-05$ \\
\hline $\operatorname{Rv} 1028 c / k d p D$ & C+205/pfpA & Pyrophosphate-fructose 6-phosphate 1-phosphotransferase & $5.00 \mathrm{E}-03$ \\
\hline Rv2857c/UNK & $\mathrm{C}+237 / \mathrm{fabG}$ & 3-Oxyacyl (acyl-carrier protein) reductase & 8.00E-37 \\
\hline Rv1238/sugC & $\mathrm{C}+202 / \mathrm{oppF}$ & Oligopeptide $A B C$ transporter protein & 3.00E- 25 \\
\hline Rv2048c/pks 12 & $\mathrm{C}+770 / \mathrm{fabF}$ & $\beta$-Ketoacyl-ACP synthase & $2.00 \mathrm{E}-21$ \\
\hline Rv3502c/UNK & $\mathrm{C}+237 / \mathrm{fabG}$ & 3-Oxyacyl (acyl-carrier protein) reductase & $8.00 \mathrm{E}-21$ \\
\hline Rv0687/UNK & $\mathrm{C}+237 / \mathrm{fabG}$ & 3-Oxyacyl (acyl-carrier protein) reductase & $9.00 \mathrm{E}-19$ \\
\hline Rv1144/UNK & $\mathrm{C}+237 / \mathrm{fabG}$ & 3-oxyacyl (acyl-carrier protein) reductase & $8.00 \mathrm{E}-18$ \\
\hline Rv1013/pks16 & C†776/aas & 2-Acylglycerophosphoethanolamine acyltransferase & $5.00 \mathrm{E}-14$ \\
\hline $\mathrm{Rv} 1185 \mathrm{c} / \mathrm{fad} 21$ & Ct776/aas & 2-Acylglycerophosphoethanolamine acyltransferase & $9.00 \mathrm{E}-06$ \\
\hline Rv2502c/accD1 & $C+265 / \operatorname{acc} A$ & Acetyl-CoA carboxylase transferase subunit $\alpha$ & $6.00 \mathrm{E}-03$ \\
\hline Rv099/fad 10 & C+776/aas & 2-Acylglycerophosphoethanolamine acyltransferase & $8.00 \mathrm{E}-02$ \\
\hline Rv2692/trkB & $\mathrm{C}+714 / \mathrm{gps} A$ & Glycerol-3-phosphate dehydrogenase & $9.00 \mathrm{E}-02$ \\
\hline Rvilllc/UNK & $\mathrm{C}+451 / \mathrm{cds} \mathrm{A}$ & Phosphatidate cytidylytransferase (CDP diglyceride) & $3.00 \mathrm{E}-01$ \\
\hline Rv3556c/fadA6 & $\mathrm{C}+770 / \mathrm{fabF}$ & $\beta$-Ketoacyl-ACP synthase & 7.00E-01 \\
\hline \multicolumn{4}{|c|}{ Cell envelope related: } \\
\hline Rv1109c/UNK & $\mathrm{C}+414 / p m p C$ & Outer membrane protein C (Chlamydia-specific) & $3.00 \mathrm{E}-01$ \\
\hline $\mathrm{R} v 3484 / \operatorname{cps} A$ & $\mathrm{C}+414 / \mathrm{pmpC}$ & pmpC : outer membrane protein C (Chlamydia-specific) & 6.00E-01 \\
\hline Rv2335/cysE & $\mathrm{C}+243 /$ firA & UDP-3-O-(3-hydoxymyristoyl)-glucosamine- $N$-acyltransferase & $1.00 \mathrm{E}-02$ \\
\hline Rv2335/cysE & $C+531 / / p x A$ & UDP- $N$-acetylglucosamine acyltransferase & $1.00 \mathrm{E}-02$ \\
\hline Rv2981/ddlA & Ct762/murC & MUR-NAc-L-alanine and D-alanine-D-alanine ligase & $2.00 \mathrm{E}-36$ \\
\hline \multirow{2}{*}{\multicolumn{4}{|c|}{ Probable $N$-acetylmuramoyl-I-alanine amidase }} \\
\hline & & & \\
\hline $\mathrm{Rv} 2921 \mathrm{c} / \mathrm{fts} Y$ & $\mathrm{C}+820 / \mathrm{fts} Y$ & Signal recognition particle & $6.00 \mathrm{E}-46$ \\
\hline Rv3870/UNK & $\mathrm{C}+739 / \mathrm{ftsK}$ & Cell division protein (ATPase) & $1.00 \mathrm{E}-13$ \\
\hline Rv3871/UNK & $\mathrm{C}+739 / \mathrm{ftsK}$ & Cell division protein (ATPase) & 8.00E-02 \\
\hline Rv2912c/UNK & $\mathrm{C}+570 / \mathrm{gspF}$ & Type II secretion pathway protein (protein F) & $6.80 \mathrm{E}-01$ \\
\hline $\mathrm{Rv} 1821 / \sec A 2$ & $\mathrm{C}+701 / \sec A$ & Preprotein translocase subunit $A$ protein & $1.00 \mathrm{E}-62$ \\
\hline \multicolumn{4}{|c|}{$\begin{array}{l}\text { Transport and binding: } \\
\text { Trecen }\end{array}$} \\
\hline Rv1469/ctpD & $\mathrm{C}$ 727/zntA & Cation-transporting ATPase & $1.00 \mathrm{E}-78$ \\
\hline Rv3270/ctpC & $\mathrm{C}+727 / z n+A$ & Cation-transporting ATPase & $2.00 \mathrm{E}-65$ \\
\hline Rv1272c/UNK & $\mathrm{C}+264 / \mathrm{msbA}$ & $A B C$ transporter protein, MSD-NBD fusion protein & $2.00 \mathrm{E}-56$ \\
\hline $\mathrm{Rv} 3663 \mathrm{c} / \mathrm{dppD}$ & $C+689 / 690 / 201 / 202$ & Oligopeptide $A B C$ transporter protein & $7.00 \mathrm{E}-46$ \\
\hline Rv2936/drrA & $\mathrm{C}+653 /$ yhbG & Probable $A B C$ transporter atp binding protein & $2.00 \mathrm{E}-27$ \\
\hline Rv0655/UNK & $C+130 / g \ln Q$ & Glutamine $A B C$ transporter & $1.00 \mathrm{E}-23$ \\
\hline Rv3758c/proV & $\mathrm{C}+130 / 180 \mathrm{~g} \ln Q /$ tau $B$ & ABC transporter, ATP-binding protein & $6.00 \mathrm{E}-23$ \\
\hline Rv2038c/UNK & $\mathrm{C}+202 / 689$ & $A B C$ transporter protein & $2.00 \mathrm{E}-20$ \\
\hline Rv3781/UNK & C+653/yhbG & Probable ABC transporter ATP-binding & $1.00 \mathrm{E}-11$ \\
\hline Rv3501c/UNK & $\mathrm{Ct}+194 / \mathrm{mgtE}$ & $\mathrm{Mg}^{2+}$ transport protein & 4.00E-01 \\
\hline Rv2813/UNK & $C+130 / g \ln Q$ & Glutamine $A B C$ transporter & $1.00 \mathrm{E}+00$ \\
\hline \multicolumn{4}{|l|}{ 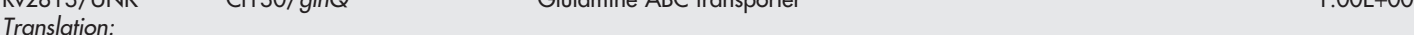 } \\
\hline Rv2845c/proS & C+393/proS & Prolyl-tRNA synthetase & $4.00 \mathrm{E}-88$ \\
\hline Rv1640c/lys X & Ct781/lysS & Lysyl tRNA synthetase & $9.00 \mathrm{E}-69$ \\
\hline Rv3375/amid & Ct003/gluA & Glu-tRNA Gln amidotransferase subunit & $1.00 \mathrm{E}-52$ \\
\hline Rv3419c/gcp & $\mathrm{C}+197 / \mathrm{gcp} 2$ & O-Sialoglycoprotein endopeptidase & $6.00 \mathrm{E}-49$ \\
\hline Rv3560c/fadE30 & C+437/fusA & Elongation factor $G$ protein & $6.00 \mathrm{E}-01$ \\
\hline Rv3563/fadE32 & $C+437 /$ fus A & Elongation factor $G$ protein & $6.00 \mathrm{E}-01$ \\
\hline Rv3210c/UNK & $\mathrm{C}+459 / \mathrm{prfB}$ & Peptide chain release factor RF-2 & $8.60 \mathrm{E}-01$ \\
\hline Rv0101/nrp & Ct766/miaA & 2-Acylglycerophosphoethanolamine acyltransferase & 4.00E-04 \\
\hline \multicolumn{4}{|c|}{ Regulatory functions: } \\
\hline Rv2374c/hrcA & $\mathrm{C}+394 / \mathrm{hrcA}$ & Heat inducible transcription regulator $\mathrm{HrcA}$ & $1.00 \mathrm{E}-14$ \\
\hline Rv3246c/mtrA & C+468/pilR & Two component sensor system regulatory subunit & 3.00E-08 \\
\hline $\mathrm{Rv} 0490 / \operatorname{sen} X 3$ & $\mathrm{C}+467 / \mathrm{pils}$ & Two component sensor histidine kinase (ATOS related) & $2.00 \mathrm{E}-07$ \\
\hline Rv2483c/UNK & Ct743/hctA & $\mathrm{Hcl}$ histone analogue & $2.00 \mathrm{E}-04$ \\
\hline \multicolumn{4}{|c|}{ Biosynthesis of cofactors: } \\
\hline Rv2388c/hemN & Ct052/hemN & Oxygen independent coproporphyrinogen III oxidase & $2.00 E-34$ \\
\hline Rv1569/biof & $\mathrm{C}+777 / \mathrm{bioF}$ & 8-Amino-7-oxononanoate synthase & $2.00 \mathrm{E}-20$ \\
\hline Rv1568/bioA & $\mathrm{C}+210 /$ hemL & Glutamate-1-semialdehyde 2,1-aminomutase & $9.00 \mathrm{E}-16$ \\
\hline \multirow{2}{*}{\multicolumn{4}{|c|}{ Chlamydia other and uncategorised: }} \\
\hline & & & \\
\hline Rv3877/UNK & Ct115/UNK & Hypothetical protein (basic) & $2.00 \mathrm{E}-01$ \\
\hline Rv3910/UNK & $\mathrm{C}+624 / \mathrm{mviN}$ & MviN virulence factor & 8.00E-09 \\
\hline Rv0670/end & $\mathrm{C}+625 /$ end 4 & Endonuclease iv & $2.00 \mathrm{E}-16$ \\
\hline Rv3876/UNK & $\mathrm{C}+868 / \mathrm{UNK}$ & Conserved hypothetical protein & $2.00 \mathrm{E}-08$ \\
\hline Rv3103c/UNK & C+868/UNK & Conserved hypothetical protein & $9.00 \mathrm{E}-06$ \\
\hline Rv3683/UNK & $\mathrm{C}+461 /$ UNK & Conserved hypothetical protein & $2.00 \mathrm{E}-05$ \\
\hline Rv1021/UNK & $\mathrm{C}+255 /$ UNK & Conserved hypothetical protein (acidic) & $9.00 \mathrm{E}-05$ \\
\hline Rv3400/UNK & $\mathrm{C}+464 / \mathrm{UNK}$ & Conserved hypothetical protein & $1.00 \mathrm{E}-04$ \\
\hline Rv0171/UNK & C+868/UNK & Conserved hypothetical protein & $2.00 \mathrm{E}-03$ \\
\hline Rv3723/UNK & C+664/UNK & Conserved hypothetical protein & 4.00E-03 \\
\hline Rv3810/pirG & $\mathrm{C}+456 /$ UNK & Conserved hypothetical protein & $5.00 \mathrm{E}-01$ \\
\hline
\end{tabular}

*UNK, gene of unknown function; $† C$ trachomatis genes indicated in bold were chosen for real time RT-PCR transcript analyses, as indicated in the text. 
monocytes were infected at a multiplicity of infection of $1: 1$ with $C$ trachomatis serovar $\mathrm{K}$, and infected cultures were harvested at day 5 after infection; cell pellets were snap frozen at $-80^{\circ} \mathrm{C}$ until processed. To be certain that chlamydiae infecting monocytes in these experiments had entered the persistent state, transcripts from the $C$ trachomatis dnaA, polA, ompl, ftsK, pyk, and gap genes were assessed by reverse transcriptase (RT)-PCR (see just below); all such transcripts were absent as expected, except those from $d n a A$ and polA, which are expressed during both active and persistent infection. ${ }^{8}$

\section{Preparation and analysis of RNA/cDNA}

Total nucleic acid preparations were made from Chlamydia infected HEp-2 and human monocyte cell pellets, and from synovial tissue samples, as described previously. ${ }^{8}$ Pure RNA was prepared from aliquots of each preparation by treatment with DNaseI (RQ1 DNase; Promega Biotech, Madison WI, USA), followed by extraction in phenol:chloroform, and collection by ethanol precipitation. Reverse transcription of total RNA preparations to cDNA was done using the MuLV enzyme and random hexamers as primers (Invitrogen, Carlsbad CA, USA), as described. ${ }^{10}{ }^{14}$

CDNA preparations were subjected to quantitative real time RT-PCR analyses for 16 targeted $C$ trachomatis genes, using the SYBR green method. ${ }^{10}{ }^{14}$ Table 2 shows the coding sequences of interest and the primer systems used in the analyses. Each real time RT-PCR assay for each targeted gene was run in triplicate independently. Data were normalised to chlamydial 16S rRNA, as described ${ }^{8}{ }^{10}$; ; data for specific transcripts in all monocyte and patient derived assays were indexed to the level of that transcript in $C$ trachomatis actively growing for 12 hours in HEp-2 cells. Assays were done using a PE Biosystems (Foster City, CA, USA) model 7700 sequence detector; data were analysed using version 1.9 sequence analysis software from PE Biosystems.

\section{RESULTS}

\section{C trachomatis genes orthologous to $M$ tuberculosis persistence related genes}

To determine whether any of the 194 genes from $M$ tuberculosis identified as being required for growth and persistence in vivo in mice ${ }^{22}$ have orthologues in $C$ trachomatis, we performed a BLAST evaluation of each identified mycobacterial coding sequence against the full chlamydial genome (http://www.stdgen.lanl.gov, accessed 7 December 2005). Of the 194 genes, we identified 67 orthologues with Expect values of $10^{-1}$ or better, representing $35 \%$ of the total number of genes assessed. Table 3 provides a complete list of the chlamydial coding sequences identified, their related genes in $M$ tuberculosis, and the Expect values. The chlamydial orthologues of mycobacterial persistence related genes identified fall into general categories similar to those in the $M$ tuberculosis study-that is, genes encoding products involved in cell envelope synthesis or modification, synthesis of cofactors, transport, translation, and so on. ${ }^{22}$ Interestingly, nine genes specifying proteins of unknown function were identified on the $C$ trachomatis genome, all but one of which corresponded to similarly unknown genes in $M$ tuberculosis. No genes specifying components of the chlamydial type III secretion system were identified, but $\sec A$, a component of an apparent type II secretion system, was identified (but see below). Three secretion related mycobacterial genes were shown to be up regulated in the earlier study, including $\sec A 2$.

A few potentially important differences emerged in the panel of chlamydial orthologues identified. For example, we showed earlier that expression of genes encoding products for the glycolytic and pentose phosphate pathways is severely attenuated in persistent $C$ trachomatis cells, ${ }^{9}$ while transcription of several genes involved in energy production and conversion were shown to be up regulated in the mycobacterial study. Importantly, 107 of the 194 genes identified in the mycobacterial study as required for in vivo growth and persistence were coding sequences of unknown function; the majority of these 107 genes had no orthologous coding sequence in C trachomatis (see "Discussion").

\section{Expression of selected $C$ trachomatis orthologues during persistent infection in vitro}

To confirm that the Chlamydia genes identified are not only expressed during persistent infection but also up regulated over their level of expression during active infection, we selected 16 chlamydial orthologues from various functional

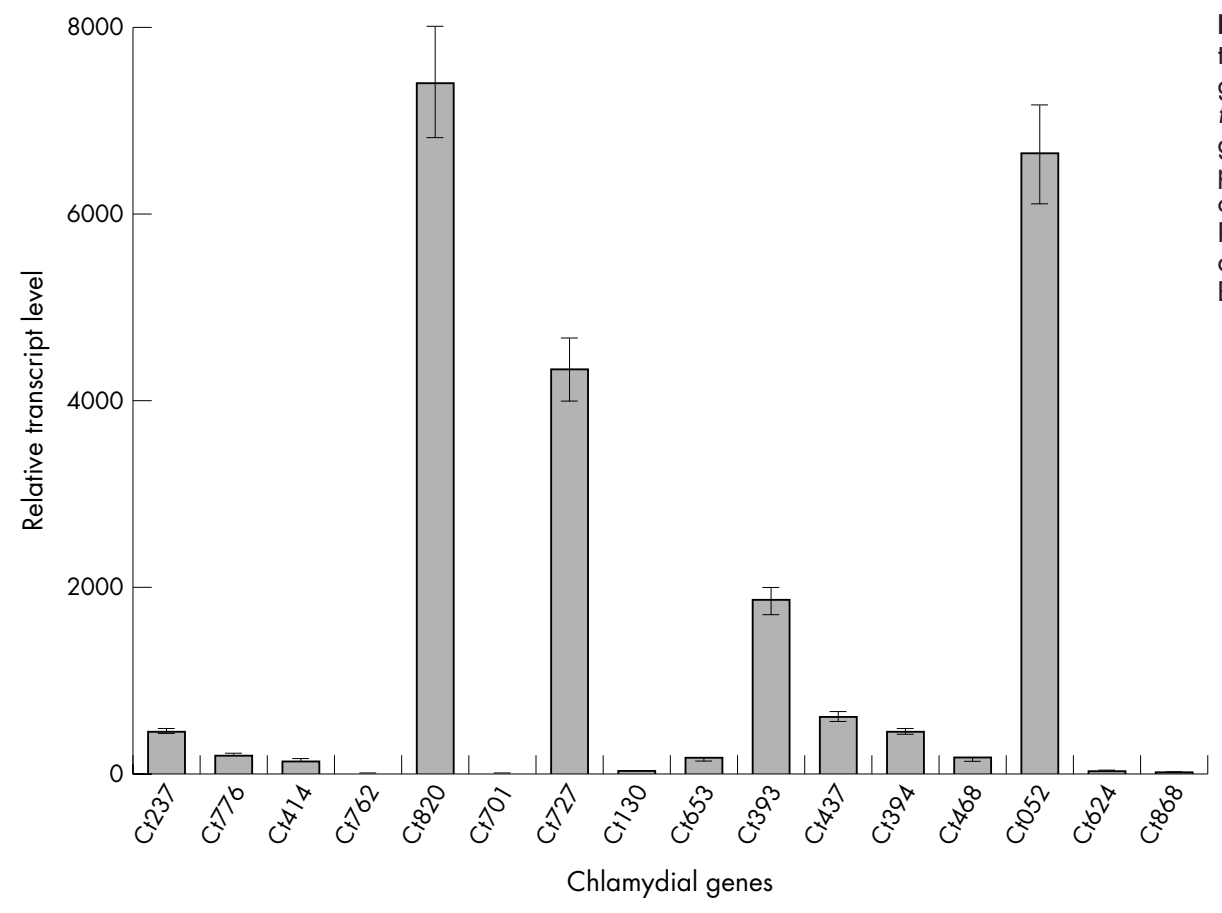

Figure 1 Real time RT-PCR analysis of transcript levels from $16 \mathrm{C}$ trachomatis genes identified as orthologous to $M$ tuberculosis genes required for in vivo growth and persistence, using CDNA prepared from an in vitro model of chlamydial persistence. Preparation of RNA/cDNA and details of the analyses are given in "Patients and methods". Bars represent standard error. 


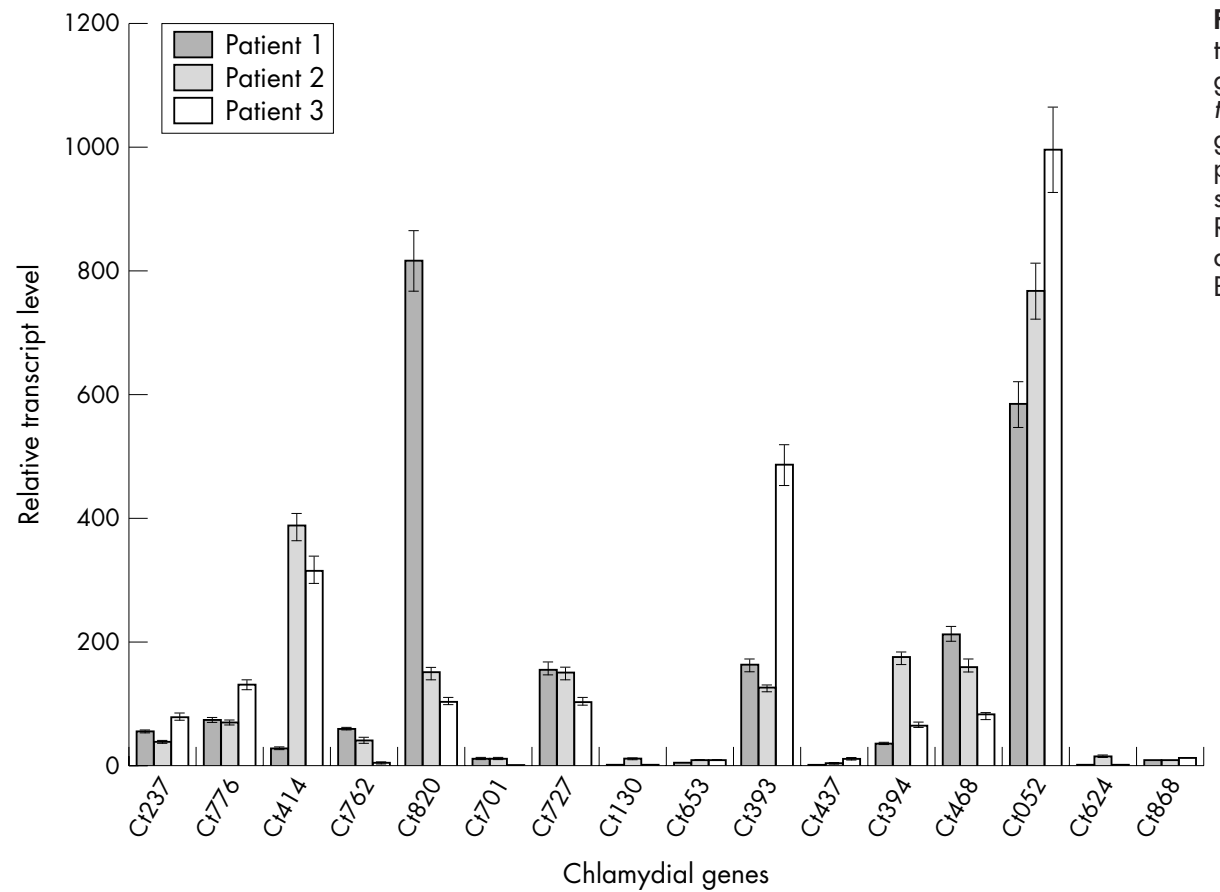

Figure 2 Real time RT-PCR analysis of transcript levels from $16 \mathrm{C}$ trachomatis genes identified as orthologous to $M$ tuberculosis genes required for in vivo growth and persistence, using cDNA prepared from Chlamydia infected synovial tissue samples. Preparation of RNA/cDNA and details of the analyses are given in "Patients and methods". Bars represent standard error.

categories and assessed their relative expression level by real time RT-PCR during both infection states; the genes subjected to this analysis are indicated in bold in table 3.

In previous studies of chlamydial persistence, we have employed an in vitro model system using normal human monocytic cells infected with $C$ trachomatis serovar $\mathrm{K}$; in this system, chlamydiae transit from a more or less normal infection state to the persistent state by 3 days after infection. ${ }^{7-10}$ We analysed RNA from infected monocytes at day 5 after infection and compared transcript levels from each of the 16 targeted genes with the level of their expression at 12 hours after infection during active infection of HEp-2 cells. Previous microarray based studies have shown that all coding sequences on the $C$ trachomatis chromosome and plasmid are expressed at some time during the normal developmental cycle. ${ }^{24}{ }^{25}$ Consistent with those data, each of the 16 genes assessed here was being transcribed at 12 hours after infection in HEp-2 cells (data not shown).

Figure 1 provides a summary of the transcript level at day 5 after infection in the in vitro monocyte model system for each of the 16 chlamydial genes targeted relative to their expression level during active HEp-2 cell infection. Interestingly, all but four of the chlamydial genes assayed showed relatively strong up regulation during persistence in comparison with expression during active infection. The four genes showing no/minimal transcriptional up regulation during persistence were Ct762 (murC/murF, an apparent fusion protein with MUR-NAC-L-alanine and D-alanine-Dalanine ligase activity), Ct701 ( $\sec A$, preprotein translocase subunit A protein), Ct624 (mviN, a putative virulence factor), and Ct868 (hypothetical protein, possibly a membrane thiol protease). Four other chlamydial orthologue genes showed powerful up regulation of expression during persistence, consistent with data from the mycobacterial study. These were Ct820 (fts $Y$, component of signal recognition particle), Ct727 (zntA/cadA, cation-transporting ATPase), Ct393 (proS, prolyl-tRNA synthetase), and Ct052 (hemN, oxygen independent coproporphyrinogen III oxidase). All other chlamydial genes assessed showed moderate to fairly strong transcriptional up regulation in persistent $C$ trachomatis compared with that shown in actively infecting organisms.

\section{Expression of selected $C$ trachomatis orthologues during persistent infection in vivo}

With one interesting exception, the human monocyte model of $C$ trachomatis persistence has proved to be extremely accurate in reflecting the pattern of chlamydial gene expression in vivo in synovial tissues. ${ }^{8} 9$ That exception was the identification of a different transcript pattern from the chlamydial groEL gene (Ct1l0, encodes the authentic heat shock protein (hsp)60) between the monocyte model of persistence and synovial tissue samples from patients with Chlamydia associated arthritis ${ }^{10}$; we understood this observation to indicate that the cellular context in the synovium differs in important ways from that of pure monocytic cells in culture.

To determine whether in vivo and in vitro expression differed for any of the 16 tested chlamydial persistence orthologue genes, we repeated the real time RT-PCR assays using RNA/cDNA prepared from synovial biopsy specimens of three patients with arthritis known to be PCR positive for $C$ trachomatis in that tissue. Figure 2 presents the results of those assays. The Ct820, Ct727, Ct393, and Ct052 genes all showed expression in these patient samples, as they did in the monocyte model of chlamydial persistence. However, the genes that displayed essentially no up regulation of expression in the monocyte system (Ct762, Ct701, Ct624, Ct868) all showed some level of increased expression in the patient samples, consistent with data from the mycobacterial study.

Ct414 ( $p m p C$, polymorphic membrane protein), Ct394 ( $h r c A$, transcriptional repressor), and Ct468 (pilR/atoC, sensor subunit of a two-component system) all showed similar levels of expression in one or more of the patient samples relative to that found in the monocyte model of persistence. Ct776 (aas, 2-acylglycerophosphoethanolamine acyltransferase) and Ct437 (fusA, elongation factor G protein) also were expressed at generally the same levels in patient samples as in the in vitro monocyte system. We assume that differences in transcript levels among the three patients for the genes assessed (for example, Ct414, Ct820) were a function of disease duration and genetic and other characteristics specific to each individual; these characteristics determine the details of host-pathogen interaction for each patient, in turn 
influencing the course of pathogenesis for each individual patient.

\section{DISCUSSION}

Molecular genetic and other observations have demonstrated that $C$ trachomatis infecting synovial tissues in patients with Chlamydia associated arthritis are in the persistent, rather than the actively growing, state. ${ }^{23}$ Although we have some knowledge of the transcriptional and morphological characteristics of persistent Chlamydia, we have essentially no understanding of which specific aspects of host-pathogen interaction are responsible for eliciting chlamydial persistence in either the monocyte model system or in synovial materials. This lack of understanding results primarily from the absence of a system for genetic manipulation of any chlamydial species, and from the large number of genes specifying proteins of unknown function encoded by all chlamydial genomes so far sequenced. In the present report, we extrapolate to $C$ trachomatis molecular genetic data from a persistence related study of $M$ tuberculosis, an organism amenable to genetic manipulation and which undergoes persistent infection. ${ }^{1722}$ We show that $35 \%$ of the 194 mycobacterial genes identified in the parent study as showing significant transcriptional up regulation in support of persistent infection have orthologous coding sequences on the $C$ trachomatis genome. We further show that most of a selected set of those chlamydial orthologues do indeed show increased expression in an in vitro model of chlamydial persistence and in relevant patient samples, compared with their normal expression levels during active infection. Thus, the results presented here indicate that some molecular genetic details underlying chlamydial persistence can be gleaned or extrapolated from experimental work in other organisms. Most importantly, however, the data given add new details to the emerging picture of the genetic basis underlying persistent infection by $C$ trachomatis, in both a relevant in vitro system and in vivo in samples from patients with arthritis.

The genome of $M$ tuberculosis is about $4.4 \mathrm{mbp}$ in length and encodes about 4000 genes. ${ }^{26}$ Most of the 194 genes identified in the persistence study of this organism are expressed at only low level or not at all during axenic growth in culture, ${ }^{22}$ suggesting that persistence for $M$ tuberculosis may depend on expression of a particular set of genes devoted largely or exclusively to establishment of that state. In contrast, the $C$ trachomatis genome specifies just over 900 coding sequences, and all of them are expressed at one time or another during active growth of the organism. ${ }^{15} 162425$ This suggests that, unlike $M$ tuberculosis, $C$ trachomatis does not possess a gene or gene set whose sole function is the genesis and/or maintenance of the persistent infection state. Thus, while $M$ tuberculosis persistence may derive largely from expression of a specific set of genes, in $C$ trachomatis development of that state must be a function of readjustment of transcript levels from genes already being expressed. The challenge will be to understand whether, and if so by what means, that readjustment results from input from the host monocytic cell in the joint, and how that readjustment of gene expression alters chlamydial biochemistry and physiology.

It is difficult to deduce from the results presented here, and from those in the mycobacterial study, whether and if so how, metabolic processes are similarly modified overall between the actively growing and persistent infection states of these two bacterial pathogens. Although many of the $M$ tuberculosis genes up regulated during in vivo growth and persistence have known functions, the majority of genes $(107 / 194(55 \%))$ so identified encode proteins of unknown function. ${ }^{22}$ Nine of the $C$ trachomatis orthologues of mycobacterial genes found in our BLAST search also were coding sequences specifying proteins of unknown function, but importantly, most of the unknown $M$ tuberculosis genes in the persistence study were shown to be unique to that organism. As pointed out in the Sassetti and Rubin study, these observations indicate that mycobacteriae appear to have evolved mechanisms for in vivo survival and persistence that are unique-that is, not shared by other obligate or facultative intracellular pathogens. Similarly, most coding sequences specifying products of unknown function in the $C$ trachomatis genome are either Chlamydia- (genus-) specific or specific to that organism, probably indicating that the genetic underpinnings of chlamydial persistence are essentially unique to this group as well. Indeed, we suspect that many critical molecular genetic and other details differ between these two organisms in their metabolic and other characteristics of persistence. None the less, while caution must be exercised in extrapolating the genetic mechanisms underlying persistence in one organism to those performing a similar function in another, circumspect exercise of such extrapolations can be useful.

The panel of $M$ tuberculosis genes underlying in vivo growth and persistence, and the group of $C$ trachomatis genes identified as orthologous to them, fall into the same general functional categories, with the exception that the former panel included more genes encoding lipid metabolism related products than did the latter. As mentioned, given the limited panel of chlamydial genes identified as being orthologous to mycobacterial persistence related genes, it is difficult to form a detailed picture of the overall transcript pattern underlying chlamydial persistence in monocytic cells, and the overall metabolic characteristics of persistence for the organisms that result from that gene expression pattern. One study provided a transcriptome analysis of chlamydial gene expression in an in vitro model of persistence which was different from the monocyte system used here. ${ }^{27}$ Collaborative studies between this laboratory and another have shown, however, that the profiles of gene expression differ importantly among the several currently employed in vitro model systems of persistence studied in various laboratories (Klos A, HCG, APH, unpublished observations). In the case of the monocyte model of chlamydial persistence, which we consider to be the most relevant for studies of pathogenesis in Chlamydia associated arthritis, understanding the transcriptional and metabolic modifications underlying persistence must derive from full transcriptome analyses of that system. We are now performing those analyses.

\section{ACKNOWLEDGEMENTS}

This work was supported by grants AR-42541 (APH), AR-47186 (HCG), and AI-44493 (JAW-H) from the US National Institutes of Health

\section{Authors' affiliations}

H C Gérard, J A Whittum-Hudson, A P Hudson, Department of Immunology and Microbiology, Wayne State University School of Medicine, Detroit Ml 48201, USA

H R Schumacher, Department of Medicine, Division of Rheumatology, University of Pennsylvania School of Medicine and Medical Research Department Veterans Affairs Medical Center, Philadelphia PA 19104, USA

A P Hudson, Medical Research, Department of Veterans Affairs Medical Center, Detroit MI 48201, USA

Competing interest: None.

\section{REFERENCES}

1 Schachter J. Infection and disease epidemiology. In: Chlamydia: intracellular biology, pathogenesis, and immunity, In: Stephens RS, eds. Washington DC: ASM Press, 1999:139-69. 
2 Villareal C, Whittum-Hudson JA, Hudson AP. Persistent Chlamydiae and chronic arthritis. Arthritis Res 2002;4:5-9.

3 Gérard HC, Whittum-Hudson JA, Schumacher HR, Hudson AP. Chlamydiae and inflammatory arthritis. In: Focus on arthritis research, In: Columbus F, eds. New York: Nova Science Publishers, 2004:175-99.

4 Hatch TP. Developmental biology. In: Chlamydia: intracellular biology, pathogenesis, and immunity, In: Stephens RS, eds. Washington DC: ASM Press, 1999:29-67.

5 Moazed TC, Kuo CC, Grayston JT, Campbell LA. Evidence of systemic dissemination of Chlamydia pneumoniae via macrophages in the mouse. $J$ Infect Dis 1998;177:1322-5.

6 Koehler L, Nettelnbreker E, Hudson AP, OH N, Gerard HC, Branigan PJ, et al. Ultrastructural and molecular analysis of the persistence of Chlamydia trachomatis (serovar K) in human monocytes. Microb Pathog 1997;22:133-42

7 Gérard HC, Köhler L, Branigan PJ, Zeidler H, Schumacher HR, Hudson AP. Viability and gene expression in Chlamydia trachomatis during persistent infection of cultured human monocytes. Med Microbiol Immunol 1998; 187:115-20.

8 Gérard HC, Krauße-Opatz B, Rudy D, Rao JP, Zeidler H, Schumacher HR, et al. Expression of Chlamydia trachomatis genes required for DNA synthesis and cell division in active vs. persistent infection. Mol Microbiol 2001:41:731-41.

9 Gérard HC, Freise J, Rudy D, Krauß-Opatz B, Köhler L, Zeidler H, et al. Chlamydia trachomatis genes whose products are related to energy metabolism are expressed differentially in active vs. persistent infection. Microb Infect 2002;4:13-22.

10 Gérard HC, Whittum-Hudson JA, Schumacher HR, Hudson AP. Differential expression of the three Chlamydia trachomatis hsp60-encoding genes in active vs persistent infection. Microb Pathog 2004;36:35-9.

11 Wang SA, Papp JR, Stamm WE, Peeling EW, Martin DH, Holmes KK, et al. Evaluation of antimicrobial resistance and treatment failures for Chlamydia trachomatis: a meeting report. J Infect Dis 2005; 191:917-23.

12 Hogan RJ, Mathews SA, Mukhopadhyay S, Summersgill JT, Timms P. Chlamydial persistence: beyond the biphasic paradigm. Infect Immun 2004;72:1843-55.

13 Schumacher HR, Gérard HC, Arayssi TK, Pando JA, Branigan PJ, Saaibi DL, et al. Chlamydia pneumoniae is present in synovial tissue of arthritis patients with lower prevalence than that of $C$. trachomatis. Arthritis Rheum 1999;42:1889-93.
14 Byrne GI, Ouellette SP, Wang Z, Rao JP, Lu L, Beatty WL, et al. Chlamydia pneumoniae expresses genes required for DNA replication but not cytokinesis during persistent infection of HEp-2 cells. Infect Immun 2001;69:5423-9.

15 Stephens RS, Kalman S, Lammel C, Fan J, Marathe R, Aravind L, et al. Genome sequence of an obligate intracellular pathogen of humans: Chlamydia trachomatis. Science 1998;282:754-9.

16 Read TD, Brunham RC, Shen C, Gill SR, Heidelberg JF, White O, et al. Genome sequences of Chlamydia trachomatis MoPn and Chlamydia pneumoniae AR39. Nucleic Acids Res 2000;28:1397-406.

17 Stewart GR, Robertson BD, Young DB. Tuberculosis: a problem with persistence. Nat Rev Microbiol 2003;1:97-105.

18 Zahrt TC. Molecular mechanisms regulating persistent Mycobacterium tuberculosis infection. Microbes Infect 2003;5:159-167.

19 Master S, Zahrt TC, Song J, Deretic V. Mapping of Mycobacterium tuberculosis katG promoters and their differential expression in infected macrophages. J Bacteriol 2001;183:4033-9.

20 Zahrt TC, Deretic V. Mycobacterium tuberculosis signal transduction system required for persistent infections. Proc Natl Acad Sci USA 2001;98:12706-11.

$21 \mathrm{He} \mathrm{H}$, Zahrt TC. Identification and characterization of a regulatory sequence recognized by Mycobacterium tuberculosis persistence regulator MprA. $J$ Bacteriol 2005; 187:202-12.

22 Sassetti CM, Rubin EJ. Genetic requirements for mycobacterial survival during infection. Proc Natl Acad Sci USA 2003;100:12989-94.

23 Schumacher HR, Kulka JB. Needle biopsy of the synovial membrane: experience with the Parker-Pearson technique. N Engl J Med 1972;286:416-19.

24 Belland RJ, Zhong G, Crane DD, Hogan D, Sturdevant D, Sharma J, et al. Genomic transcriptional profiling of the developmental cycle of Chlamydia trachomatis. Proc Natl Acad Sci USA 2003;100:8478-83.

25 Nicholson TL, Olinger L, Chong K, Schoolnik G, Stephens RS. Global stagespecific gene regulation during the developmental cycle of Chlamydia trachomatis. J Bacteriol 2003;185:3179-89.

26 Cole ST, Brosch R, Parkhill J, Garnier T, Churcher C, Harris D, et al. Deciphering the biology of Mycobacterium tuberculosis from the complete genome sequence. Nature 1998;393:537-44.

27 Belland RJ, Nelson DE, Viro D, Crane DD, Hogan D, Sturdevant D, et al. Transcriptome analysis of chlamydial growth during IFN- $\gamma$-mediated persistence and reactivation. Proc Natl Acad Sci USA 2000;100:15971-6. 